\title{
Authorial Voice Behind the Use of Multimodal Metaphors in Fashion Magazine Advertising
}

\author{
Victoria Martín de la Rosa \\ Complutense University, Madrid \\ mvmartin@ucm.es
}

\begin{abstract}
This paper proposes the integration into a coherent whole of current insights from two linguistic approaches, cognitive and systemic functional linguistics, with the aim of trying to develop an analytical tool that will allow users a deeper understanding when examining advertising discourse, which is characterized by relying on a multimodal universe since two are the semiotic modes used: language and pictures. Under this framework, two different advertisements, taken from two magazines, Telva and Gentleman, have been analyzed with specific attention to the role of the authorial voice. The goal is twofold: firstly to investigate how, in every advertisement, this multimodality works towards presenting a particular product from a very desirable and attractive perspective; and secondly to unravel the values and ideology behind the use of this type of discourse. The results show that values such as those of exclusivity or refinement (first advert) or having a perfect shape (second advert) are highly valued in the culture where those adverts are embedded.
\end{abstract}

\section{Introduction}

The aim of this paper is to explore advertising discourse, as shown in two advertisements extracted from several popular magazines targeted at audiences in their thirties such as Telva and Gentleman, as two important fashion magazines being read by millions of women (Telva) and men (Gentleman). A combination of two linguistic 
approaches is used: cognitive linguistics and systemic functional linguistics in an attempt to bring together an analytical apparatus that allows users a more insightful approach into a discourse which is multimodal as it relies on two semiotic modes: language and image.

On the one hand, cognitive linguistics, which has developed over the last three decades, is followed as an approach to language that is based on our experience of the world and the way we perceive it and conceptualize it. In other words, our conceptualization of the world is stored in our everyday language and, thus, is reflected in the way we express ourselves (Lakoff, 1987, 1993; Lakoff and Johnson 1999; 2003; Johnson, 1987; Forceville, 1994, 1996, 2006, 2007, 2008; Gibbs, 1994; Goatly, 2007; Kövecses, 2002, 2005; Herrera and White, 2012). Within this approach, I shall be relying on the concept of metaphor, as a resource which allows us to transfer experience from a well-known domain to a less delineated domain (Lakoff and Johnson, 2003). Even more important for our purposes is the fact that by uncovering the metaphors being used in our advertisements, we can unwrap the values being promoted in the products advertised through the use of a number of mappings from the source domain (A) -the domain which will trigger the organization and understanding of the $\mathrm{B}$ domain- onto our target domain (B) (Lakoff and Johnson, 1980, 2003; Kövecses, 2002, 2005). Thus, they are instruments partly used to naturalize ideological positions without readers being aware of that.

On the other hand, I shall be dealing with a complementary perspective to metaphor, known as systemic functional linguistics, which considers function as the basis of human language and communicative activity. Thus, for this approach, which is user-oriented, an essential concept is that of "social context" as it constrains and influences the use of language we make. Within this framework we find the tool of evaluation, which is "the expression of the speaker's or writer's attitude or stance towards, viewpoint on, or feelings about the entities or propositions that he or she is talking about." (Hunston and Thompson, 2003a: 5). As the authors claim, the benefit of using this definition is that it is flexible enough to point in the direction of both ends of the evaluation: the user (as it is him/her who evaluates) and the propositions and entities which are assigned values. Then, we can see that, although metaphor and evaluation come from different frameworks, they both move in the same direction of trying to discover the ideologies of a given society; in other words, metaphor and evaluation, working in a complementary manner, allow users - when facing examples of advertising discourse- have a more insightful approach by applying tools that touch on the same issue of looking into the ideology held by a given society. Consequently, the goal is to integrate two theories that will provide a richer framework for the analysis of pictures and language when used together in advertisements.

As for the structure of this paper, I shall be dealing with four sections. The first one is devoted to a presentation of the linguistic resources used to approach the issue of advertising discourse: metaphor and evaluation. In the second section, I focus on the analysis of the different advertisements by applying the tools just mentioned. The third 
section presents a discussion of the advertisements analyzed. Finally, section four deals with the conclusions reached in this paper.

\section{Theoretical framework}

Firstly, I will focus on the concept of metaphor by looking at some of the studies carried out in the domain of verbal metaphor, as most of the research has been done in that area, to try to apply that vocabulary to the domain of visual metaphor when analyzing advertisements, following the example set by Forceville (1994, 1996, 2006, 2007, 2008), the first to introduce a comprehensive theory of pictorial metaphor in advertising, after claiming that more work was needed in order to show that the occurrence of metaphor is a matter of thought and, as such, is not restricted to language. Secondly, I will comment on the concept of evaluation, as the other linguistic device which will be used and pursued in this paper to unravel the value system of our community and, more particularly, the desirable qualities that are projected over the product being advertised. Finally, I will discuss briefly the work by Barthes (1978) to address the verbal side in metaphors. This is a very important component when it comes to interpreting the polysemous images used in advertisements, which means that without the verbal support viewers would, often times, be lost between competing and possible readings.

\section{A. Metaphor}

It is accepted that metaphor is an essential tool of conceptualization in everyday life and in disciplines such as mathematics (Lakoff and Núñez, 2000), education (Martín and Lazaro, 2011), business (White, 1997) or advertising (Cortés de los Rios, 2010), to mention but a few. The view of metaphor followed in this paper is the one illustrated by Lakoff and Johnson, as mentioned above, where metaphor is seen as "understanding and experiencing one kind of thing in terms of another" (1980: 5). At any rate, instead of focusing just on the verbal side of metaphor, which is the area where most of the research has been carried out by scholars, I will pursue an analysis of metaphor both in its visual and verbal component following Kennedy and Forceville, and some other scholars such as Carroll (1994). Kennedy (1982, 1993) studied metaphor in pictures by applying Richard's (1971) well-known concepts of tenor (primary subject) and vehicle (secondary subject). Forceville (1994, 1996, 2006, 2007, 2008), on the other hand, studied metaphor in advertisements and produced a theory of pictorial metaphor in advertising which offers an insightful model for analysis. In developing this theory, Forceville's claim was that if Lakoff and Johnson (1980, 1999, 2003) were right in saying that metaphors are essential to thinking, then they should be present not only in language but, for instance, in images or in music as well.

Forceville stated that, as in the verbal version, in each pictorial metaphor there is a mapping of a number of features of the domain of secondary subject ("source domain") onto the domain of the primary subject ("target domain"), which is a way of 
shedding light just on those features or aspects of the product that want to be highlighted. The advertiser is thus pushing readers' minds through the intended reading and, subsequent, cognitive effects that will result, hopefully, in buying the product. The main questions leading his analytical apparatus were: "¿What are the two terms of the metaphor and how do we know? Which of the two terms is the literal A-term and which is the figurative B-term? And what can be said about the property transfer from B to A?" (1994: 2). The same guiding questions will be used for the analysis of the advertisements.

Forceville introduced some important changes to his theory in 2006 and the label of pictorial metaphor was later adapted distinguishing two main categories of metaphorical realizations: monomodal, that is, either verbal or pictorial; and multimodal, consisting in a combination of different modes of communication such as the verbo-pictorial (2006: 390). It must be said that the theory of pictorial metaphor, as is commonly known, has become so important to metaphor analysis that it is "the most examined non-verbal mode of metaphor" (Forceville, 2008: 464).

Secondly, as a general framework, I follow Black's new interaction view as presented in Ortony (1993: 27-28). The main lines of such theory are reproduced below: 1) A metaphorical statement has two distinct subjects, identified as the primary and the secondary subject. 2) The secondary subject is to be regarded as a system rather than an individual thing. 3) The metaphorical utterance works by "projecting upon" the primary subject a set of "associated implications," comprised in the implicative complex, that are predicable of the secondary subject. 4) The maker of a metaphorical statement selects, emphasizes, suppresses, and organizes features of the primary subject by applying to it statements isomorphic with the members of the secondary subject's implicative complex. 5) In the context of a particular metaphorical statement, the two subjects "interact" in the following ways: a) the presence of the primary subject incites the hearer to select some of the secondary subject's properties; b) invites him to construct a parallel implication-complex that can fit the primary subject; and c) reciprocally induces parallel changes in the secondary subject. Then, Black's statement (1993: 35) that metaphors are creative instruments " [...] indispensable for perceiving connections that, once perceived, are then truly present" is given the highest importance; in other words, according to Black, the creative power of metaphors is such that the similarity claimed between the two domains is actually brought about by the production of the metaphor. The interesting part of this definition is that it emphasizes the dynamic nature of metaphor, in the sense that it requires an active audience, willing to be engaged in the creative mental process (Forceville, 2008).

\section{B. Evaluation}

The relevance of this tool for our analysis is twofold. On the one hand, it is used to express the speaker's or writer's opinion reflecting thus the value system of the community where such text has been produced. This means that the writer is doing much more than just telling the reader about his/her ideas, rather what (s)he is doing is building up the ideology behind his/her view of the world, although quite often "the 
persuasive nature of the text is hidden behind a veneer of objectivity" (Hunston, 2003b: 177), as will be seen in the adverts analyzed. Thus, metaphor and evaluation work together in the construal of a particular ideology by playing only certain notes, only those that want to be emphasized. On the other hand, it is used to construct and maintain relations between the writer and reader, anticipating his/her responses and trying to align the reader to his/her point of view, which plays a key role as it determines and anticipates the way a reader will respond to a piece of text. Both functions make evaluation a very strategic instrument to push one's point of view over others persuading and manipulating readers to see things in a certain way. In other words, through evaluation the reader is supposed to be exploiting a number of linguistic resources to present issues in a certain way and establish a relationship with the reader (Hunston and Thompson, 2003a; Hunston, 2003b; Martin and White, 2005). Thus, one of the questions guiding this paper will be the role of the authorial voice in the text, which could be worded in the following manner: is the figure of the author present in any way? Is there any type of evaluation projected over the product?

\section{Roland Barthes}

Finally, the work of Roland Barthes (1978) will be of interest as the tool to approach the verbal side in advertisements as, according to him, "all images are polysemous; they imply, underlying their signifiers, a 'floating chain' of signifieds, the reader able to choose some and ignore others." (1978: 39). It means that without the verbal support, the viewer is likely not to be able to discriminate what the intended reading was. In his work three are the types of messages discussed: the linguistic message -the main concern of this paper-, the denoted image and the connoted image. In relation to the linguistic message, he says that its two functions are: relay, which is the function mainly present in cartoons and comic strips" (1978: 41) and anchorage which is "the most frequent function of the linguistic message and is commonly found in press photographs and advertisements" (1978: 40-41). In this second function the linguistic message disambiguates the visual elements providing the viewer with the clues to interpret the message correctly. In Barthes' own words "[...] the text directs the reader through the signifieds of the image, causing him to avoid some and receive others; [...], it remote-controls him towards a meaning chosen in advance." (1978: 40). On the other hand, the distinction between denoted and connoted images is operational as, in his words "the viewer of the image receives at one and the same time the perceptual image and the cultural message." (1978: 36). Thus, in ordinary reading one is not able to separate one from the other.

The two hypotheses guiding this paper are the following:

1) The use of visual metaphor is one of the recurrent characteristics of advertising discourse and is used for mainly two reasons: a) to attract and maintain the viewer's attention; b) to imbue the product with desirable qualities, through the use of a persuasive discourse. 
2) The authorial voice is always hidden behind a veneer of objectivity, presenting the positive characteristics of the product through the voice of somebody else, never the advertiser himself/herself.

To prove the hypotheses just mentioned, the study will proceed by analyzing two different advertisements: one taken from a magazine for women, Vogue, and another from a magazine for men, Gentleman. Both publications have been selected based on one criterion, which is the fact that they are among the few magazines that can be found on the Spanish market published in the target language, English. Regarding the advertisements, they have been chosen because they illustrate the combination of both devices at work: multimodal metaphor, which plays an important role when interpreting the message, and the presence of the authorial voice, which can be traced even if the qualities projected on the products are meant to be objective and distanced from the hand of the advertiser.

\section{Analysis of advertisements}

We are going to analyze two different advertisements applying the linguistic resources discussed above: metaphor and evaluation. It will be seen that in each advertisement they both work together on presenting the product in the best possible manner by shedding light on all the intended positive qualities, in a persuasive manner (Goatly, 2007). The result is that either the emotional appeal of the product or its effectiveness in bringing about an effect on the consumer (losing weight) will work their way in the minds of viewers, following the advertiser's intention (Carroll, 1994).

\subsection{MONTBLANC WATCH advertisement}

This is a clear case of an advertisement where the association of the verbal component and the pictorial element is imposed on the minds of the interlocutors through the creation of a multimodal metaphor. Multimodality is a complex concept resulting from the fact that the viewer, when processing information, relies on two different sign systems or modes of perception, one of which may be language. This is precisely the case in the advertisement that follows, where the message is apprehended through language and through pictures.

\subsubsection{Metaphor}

Following Forceville $(1994,1996)$, the first question to be addressed in this analysis is: which are the two terms of the metaphor? The images in the foreground are a piano and a person behind it (-the world famous pianist (Lang Lang)-) and, standing out on the lower right, a branded watch (Mont Blanc) next to the logo of this well-known brand. This second set of pictorial elements is important because they already set the scene for the understanding of the image: the world of watches, particularly of a top and very 
prestigious brand very well positioned in the minds of consumers. At this point, though we do not really know what the message is about, it seems that some type of connection is being activated by invoking two domains by way of metonymy: time through the presence of a watch, and music through the presence of a piano, which are the two terms of the metaphor. Let us remind readers that in metonymy there is a "stand for" relationship as one entity is taken to stand for another. As has been shown by many researchers, metaphor and metonymy may interact in a number of ways, though it is beyond the scope of this paper (Taylor, 1995; Ruiz de Mendoza Ibáñez, 1999a \&1999b).

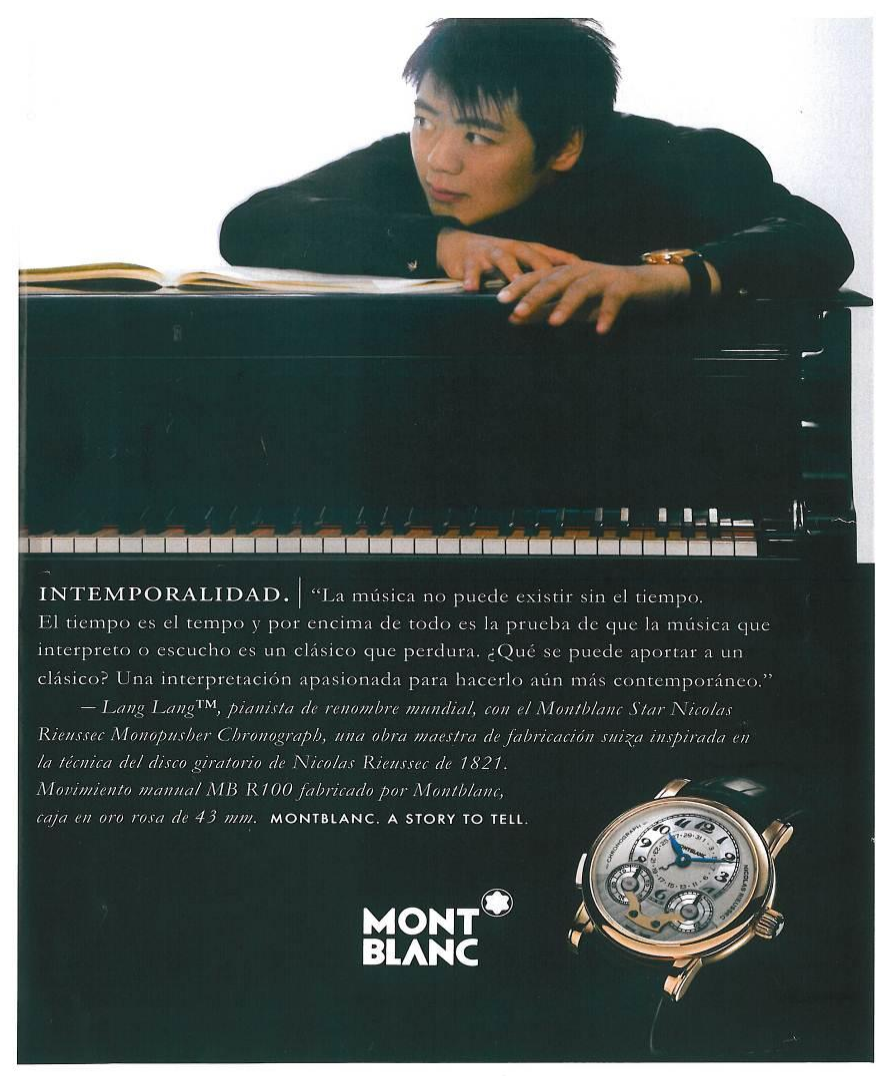

Figure 1. Montblanc Watch

Nevertheless the information provided is not enough to grasp the complete message. Thus, we need to pursue the analysis further by moving one layer up: the verbal message, which triggers new and valuable information. It is divided into three parts: the name of the brand (Montblanc), the headline and the body.

- The headline reads: INTEMPORALIDAD [TIMELESSNESS]

The headline is interesting because it goes one step further. By negating the value of the domain of time (in-temporalidad) [without time] and turning it into timeless, the advertiser is calling consumers' attention to the fact that this watch is a very valuable 
object, not affected by either the passage of time or by the dictates of fashion, to the same extent that classical music is. All these properties get projected onto the watch through the association of the watch to classical music, which is the type of music performed by the pianist in the picture.

- The body copy, which is subdivided into two parts, reads:

a) "La música no puede existir sin el tiempo. El tiempo es el tempo y por encima de todo es la prueba de que la música que interpreto o escucho es un clásico que perdura. ¿Qué se puede aportar a un clásico? Una interpretación apasionada para hacerlo aún más contemporáneo." [Music cannot exist without time. Time is tempo and above everything it is the proof that the music that I play or listen to is a classic that endures. What can you bring to a classic? A passionate interpretation to make it even more contemporary.]

b) Lang Lang, pianista de renombre mundial, con el Montblanc Star Nicolas Rieussec Monopusher Chronograph, una obra maestra de fabricación suiza inspirada en Movimiento manual MB R100 fabricado por Montblanc, caja en oro rosa de $43 \mathrm{~mm}$. [Lang Lang, world renowned pianist, with the Montbalnc Star Nicolas Rienssec Monopusher Chronograph, a Swiss-made masterpiece inspired by the revolving disk technique developed by Nicolas Rienssec in 1821. Manual movement MB R100 made by Montblanc, 43 mm. pink gold case.]

By joining the pictorial element with the verbal clues, the relationship previously hinted at between time and music is now made clear. The mention of the word music in the body, supposedly one of the terms of the metaphor, corresponds, pictorially, to the representation of a piano. On the other hand, the mention of the word time, supposedly the other term of the metaphor, is pictorially rendered through the depiction of the watch being advertised. This shows how language tends to be more abstract than pictorial representations: the verbal component aiming at the more abstract terms, time and music, and the pictorial side working on the more tangible terms, piano and watch. This confirms Forceville's claim when he says that pictorial metaphors have a higher degree of specificity than verbal metaphors (2008: 463).

In fact, we know that this advertisement is promoting not any kind of watch but a very particular brand: Montblanc. While WATCHES ARE MUSIC can be categorized as a monomodal metaphor of the pictorial type, verbalizing the metaphor as MONTBLANC WATCHES ARE MUSIC would strictly speaking be a multimodal metaphor, because the brand can only be rendered verbally (Forceville, 2008). Still we can move further and ask ourselves about the function of watches and music in our society. The answer is that watches are to keep track of time and also to be worn, whereas music is to be listened to. Furthermore, classical music has the property to be timeless. If we introduce these ideas into the metaphor, the result is WEARING A MONTBLANC WATCH IS LISTENING TO A TIMELESS PIECE OF MUSIC. 
On the other hand, applying Black's theory we can see that the similarity between the two terms (music and time) is not pre-existent but, rather, it has been created with the aid of the textual context. Thus, the verbal component, which clearly fulfills the function of anchoring the message conveyed by the picture, works on deepening the ties existing between the two domains (music and time) as reflected in: "la música no puede existir sin el tiempo." [music cannot exist without time.] Even more, "el tiempo es el tempo" ["time is tempo"], which works on the idea that both terms are almost phonetically identical, plus the fact that tempo, as the skeleton of music, structures time. Pursuing that line of thought, the properties projected onto the music "la música que interpreto o escucho es un clásico que perdura" [the music that I play or listen to is a classic that endures] get automatically transferred onto this type of watches as a valuable piece of commodity. And the reasoning goes on along the following lines: ¿Qué se puede aportar a un clásico? Una interpretación apasionada para hacerlo aún más contemporáneo." [What can you bring to a classic? A passionate interpretation to make it even more contemporary.] This statement projects onto the wearer of the watch, through the famous pianist, the ability to bring in your own personality and conduct your own performance, which infuses the watch with great mysticism and a powerful attraction to the mind of the potential consumer.

As for the property transfer, how do we distribute the terms? In other words, what is the metaphor's literal A-term, the PS, and what is the metaphor's figurative B-term, the SS? World knowledge or the understanding that the advertisement is for watches rather than for music is what guides the viewer in assigning the distribution of the two terms: A for Montblanc watches and B for music. The ideas transferred are those of: refinement, exclusivity, distinction and luxury.

\subsubsection{Evaluation}

The formulation chosen in this advertisement, a quote by a well-known pianist, construes an apparently monoglossic arrangement (Bakhtin, 1981) -as it does not explicitly reference the viewpoints of external voices-, where the only voice found is that of the pianist. This is so because the producer or writer, which is the voice behind the choice of such quote, is completely absent from the text, at least at first sight. In other words, it seems to be a way to convey the idea that such message has no dialogistic alternatives which need to be recognized or engaged with in the current communicative context. In fact, we know for certain that the writer, the advertiser ultimately, is behind the writing of such a message, but adopts the strategy of presenting it as if it were only the responsibility of the person in the advertisement. Thus it is an external source - a person with great authority- rather than the writer who is presented as advancing the proposition. In turn, the fact that the proposition is construed as something which is not up to discussion, that is to say which can be taken for granted, has the ideological effect of construing for the advertisement a putative reader who does not challenge this value position but rather shares it completely. The effect of such 
construction is that the proposition is taken as true or valid and the reader projected for the text has no other choice but to align him/herself with the textual voice.

The text in this advertisement is a good example of attribution. This strategy is used to dissociate the proposition in the text from the text's internal authorial voice by attributing it to some external source. At any rate, this advertisement goes one step further since, as the reporting verb introducing the external voice has been avoided, the authorial voice is not even present. Then, as there is no overt indication of the authorial voice, this leads us to the following questions: a) where exactly does the author stand in relation to the content of the proposition? b) is it a way for explicit distancing of the authorial voice from the attributed material?

At this point, we need to bring to bear the theory of relevance (Sperber and Wilson, 1986). In other words, the fact of leaving the authorial voice out of the communicative situation must be relevant for the commercial purposes of this advertisement. It seems to be a way to present a relatively impartial view of the product with the writer remaining separate from any relationship of alignment with the values communicated through the advertising of the product. The writer, the advertiser, performs the role of just conveying the views of others, not implicating in supporting the values assigned to the product. All the responsibility is, thus, delegated to the person who is quoted and who, precisely, happens to be very famous and a world leading pianist. High credibility is thus given to the product via the use of a source who has high status in a particular field, in this case the field of music, since a strong link is created between those two domains: music and time. The goal is to generate an emotional response from the reader, supposedly a person sensitive enough to appreciate that link, and to win him/her over to the values promoted for the product advertised.

\subsection{CLARINS advertisement}

This advertisement has been chosen because the exploitation of the metaphor is not as clear as in the other advert analyzed for the reasons that will be mentioned below. At any rate, consumers still come across a combination of pictorial and verbal components, in another case of multimodal metaphor, where the mappable connotations between the domains are readily available due to the cultural context we live in. Thus, in a different cultural context where having a slim figure was not something pursued and seen as valuable, the advertisement would not be felicitously construed in women's minds (Lakoff, 2005).

\subsubsection{Metaphor}

The next advertisement, which is promoting the use of an anti-cellulite cream, focuses on the way to achieve one objective: losing weight. At first sight, this advertisement is likely to be very appealing and catch many consumers attention, judging by the choice of the picture aimed at women, as losing weight has turned into both a difficult 
challenge but a very desirable goal for many women in a society with certain values, where being slim is preferred over being fat.

The objects in the foreground are: on the right hand side, the cream advertised, with the verbal message almost framing the cream; and on the left-hand side the image of a woman, seen from behind, on a bicycle as if she were having a break after riding it for a while. The viewer seems, then, invited to think of the decision to use that specific cream as the start of a journey which will satisfy the desire to look young and beautiful by losing weight. Thus the two terms of the metaphor are cream and path. Anyhow, this advertisement is an example of a difficult case where the metaphorical projection is not that clear, as will be seen later when we analyze property transfer from one domain onto the other. But let us look at the process resulting in the metaphor which could be phrased in the following way: LOSING WEIGHT IS FOLLOWING A PARTICULAR PATH. In this advertisement, the two terms of the metaphor are present in the advertisement: the cream, which, by way of metonymy, is hinting at the whole process of losing weight; and the bicycle, which, again by metonymy, is implying the traversing of a particular path.

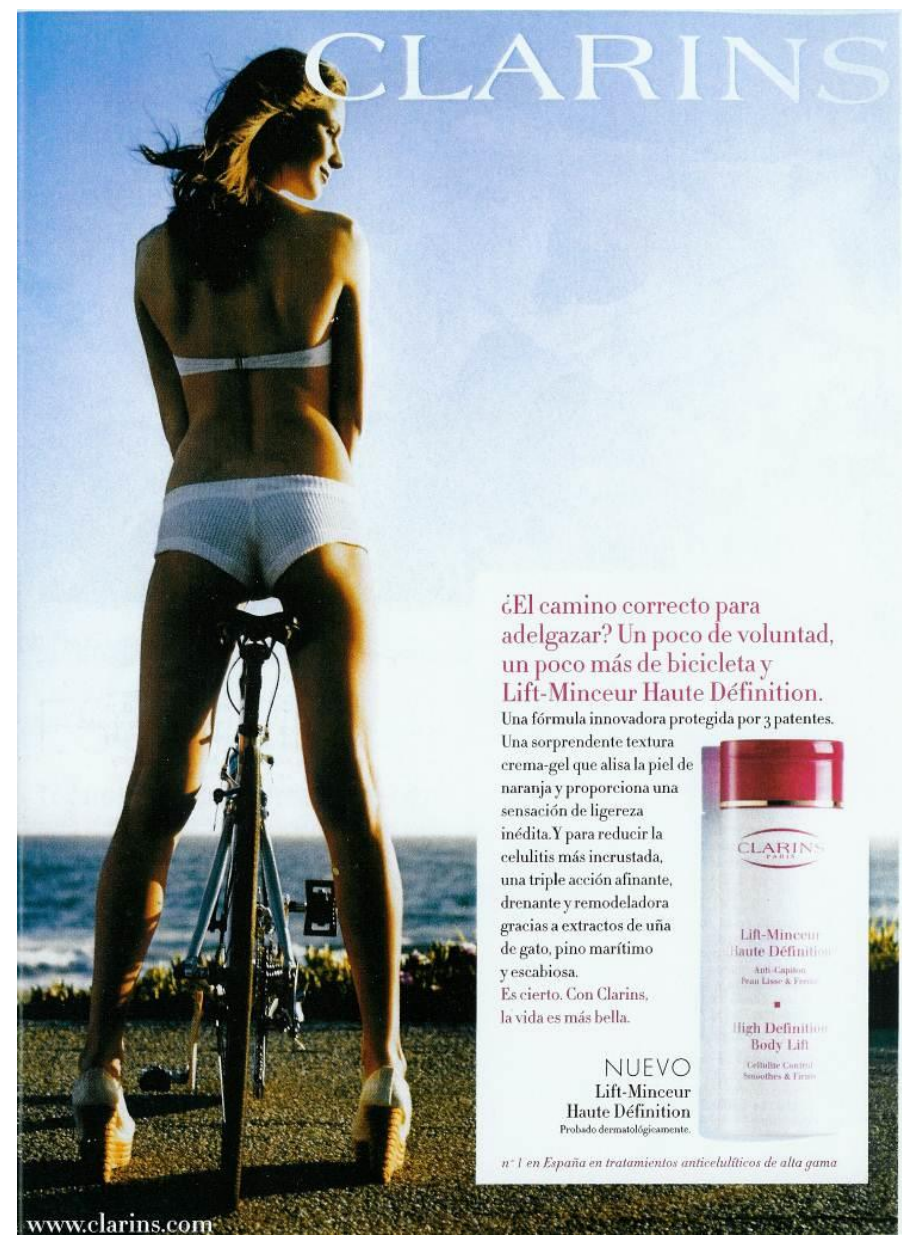

Figure 2. Lift-Minceur (Clarins) 
If, on the other hand, we invoke the verbal message, some valuable information is provided. The first thing is that the whole advertisement is structured under a key question in our society: How to be successful in a particular activity? Thus, in the verbal context, the viewer -supposedly a woman trying to lose weight- is invited to keep on reading if she is interested in the answer to that question; otherwise, she can move on. Secondly, we can see that the verbal message is basically divided into three parts: the name of the brand, the headline and the body.

- $\quad$ The name of the brand: CLARINS

- The headline reads: “¿El camino correcto para adelgazar? Un poco de voluntad, un poco más de bicicleta y Lift-Minceur haute Définition.” [The right way to lose weight? A little will-power, a little more bike, and Lift Minceur Haute Définition.]

- The body copy reads: "Una fórmula innovadora protegida por tres patentes. Una sorprendente textura crema-gel que alisa la piel de naranja y proporciona una sensación de ligereza inédita. Y para reducir la celulitis más incrustada una triple acción afinante, drenante y remodeladora gracias a extractos de uña de gato, pino marítimo y escabiosa. Es cierto. Con Clarins, la vida es más bella. [An innovative formula protected by three patents. A surprising crème-gel texture that smoothes out orange-peel skin and gives a sensation of unprecedented lightness. And to reduce the most embedded cellulite, its triple thinning, draining and reshaping action, thanks to extracts of cat claws, sea pine and scabiosa. It is true. With Clarins, life is more beautiful.]

The information given in the headline keeps exploring the metaphor by giving details of one of the terms of the metaphor: the path that the consumers need to travel to achieve the desired goal. This path is constituted by three specific ingredients: un poco de voluntad, un poco más de bicicleta y Lift-Minceur haute Définition [A little willpower, a little more bike, and Lift Minceur Haute Définition]. The fact that the name of the cream is written in French gives it an image of sophistication. Thus, since French beauty products are attributed a high level of efficacy due to the strength of their research laboratories, this product inherits this benefit of being highly efficient in the treatment offered.

As for the body copy of the advertisement, it focuses on the other term of the metaphor, the cream, which implies the whole process of losing weight. It gives information on the exact nature of the product and the reasons why this cream is true in its claims: una fórmula innovadora, una sorprendente textura crema-gel, y una triple acción. [An innovative formula, a surprising crème-gel texture, and a triple action]. A parallelism can be seen between the image and the verbal context: the bicycle, pointing to the path, finds its correlation in the headline, whereas the superb body and shape of the woman, pointing to the cream, finds its correlation in the body copy. At this point, we can say that the function of the verbal component is primarily to reinforce and complete the message already unfolded by the pictorial context. 
As far as the bicycle is concerned, a special mention must be made to it as both the representation of a bicycle and the use of the lexical term itself are specially meaningful in this context. The reason is that, as said above, it refers metonymically to the schema of the path to be travelled. Imposing a path schema (Lakoff and Johnson, 1980; Lakoff and Turner, 1989; Gibbs, 1994) on the process of losing weight makes it appear more tangible and more attainable and, as a result, distances that feeling of difficulty and frustration which women may feel when facing that challenge.

The next question is: how do we know the direction of the projection of this metaphor? In other words, what is the literal A-term, the primary subject (PS in Black's terminology) and what is its figurative B-term, the secondary subject (SS). Relying on context -pictorial context- plus world knowledge, the viewer can easily deduce that the advertisement is for creams rather than for paths. But we can go further and ask ourselves about the function of creams and paths in our society. The answer is that creams are to be applied for a specific purpose -in this case to lose weight- and paths are to be followed with the intention of reaching a destination; thus, both ideas take us to the same end-point: losing weight, which shows how well those two ideas are connected and even fused into one. Thus, the verbalization of the metaphor could be phrased as LOSING WEIGHT IS TRAVERSING A PATH.

As for property transfer, what properties are really projected from B (SS) to A (PS)? As we can see there is no clear projection of elements from B (SS) upon A (PS). Rather, more than a clear metaphor following the A is B format, what we have is an answer to the question stated at the beginning: "How to be successful in losing weight" in metaphorical terms. According to Black, since the projection of elements from $\mathrm{B}$ upon A is an essential aspect of metaphor in his theory, I will conclude that this is not a clear metaphor. Rather, this advertisement seems to be a clever way of packing lots of information into the image of the lady with a well-shaped body, cleverly associated to the image of the cream on the opposite side of the page. Thus, the connection between the two domains (having a perfect body as a result of using the cream) gets clearly established in the minds of consumers. The direction of the gaze seems to go from the left to the right: from the visible results on the perfect body of the lady to the cause that triggers such effect, the cream.

\subsubsection{Evaluation}

Pragmatically, this advertisement starts by taking for granted that there are many addressees who would be willing to know the answer to the question posed. Anyhow, the communicative situation presented, an ideal dialogue taking place between two sides, goes as far as not only asking the question but advancing the answer as if it had been required. The putative reader in this advertisement is thus women -as can be seen in the representation of a woman in the advertisement- with one objective in mind: losing weight.

The arrangement of this piece of text, as a question, construes an apparently dialogic ${ }^{1}$ communicative situation (Bakhtin, 1981) where at first sight an answer to the 
question can be provided by mentioning different and competing products. Nevertheless, this is just a way to boost its value as a product which has been acclaimed by an external voice, seemingly that of the experts. Thus, presenting the product as the alternative which has been chosen increases its value by comparison with the rest of products in the market, although this is just a marketing strategy.

As for the authorial voice, it is a type of hidden attribution because although the source of the claims made is not mentioned ("una formula innovadora protegida por tres patentes[... ] Y para reducir la celulitis más incrustrada, una triple acción afinante, drenante y remodeladora [...]") [an innovative formula protected by three patents [...]. And to reduce the most embed cellulite, its triple thinning, draining and reashing action [...]], through the choice of the very technical vocabulary, some link is established in the minds of readers between the proposition in the text and the team of researchers of the pharmaceutical company behind the creation of this cream. This strategy allows the writer (the advertiser) to remain aloof from any relationship of alignment making the reader feel completely free to decide on whether or not it is a good purchase. In other words, the relevance of presenting the situation in such a way is that, apparently, there is no reason for the potential buyer to feel (s)he is being pushed in a certain direction by the advertiser. Quite the contrary, as in the previous advertisement, the authority is delegated to a voice of authority, the pharmaceutical company.

As for the relationship construed between the writer and the putative addressee, we can see that it is that type of relationship which strongly aligns the reader into the text. The reason is that there is supposedly a difference in status between the writer and the addressee in the situation presented in such a way that the scenario that applies is an addressee who is listening attentively and receiving instructions from the writer, somebody more knowledgeable in the issue at hand. Thus, status is a resource manipulated to give greater credence to the writer's statements.

Apart from the difference in status discussed, another point is that in this interaction the focus of the communicative situation stays on the side of the people transmitting the information because they have control over it and that gives them prominence over the audience.

\section{Discussion of advertisements}

The present analysis, which pays particular attention to the ideology being held by the members of a given community through the promotion of certain values, focuses on two in print advertisements that appeared in two fashion magazines targeted at women (Telva) and men (Gentleman).

The methodology employed for the analysis of metaphors is mainly based on Forceville (1994, 1996, 2006, 2007, 2008), although other authors such as Black (1993) are also followed. At the same time, the methodology used to analyze to what extent the figure of the authorial voice is present in a more or less explicit manner, I followed 
mainly Hunston and Thompson (2003a) and Hunston (2003b), although the view of other scholars such as Bakhtin (1981) is also relied on.

To start with the presence or absence of the two terms of the metaphor, both feature in all adverts analyzed. In figure 1 and to a less extent in figure 2, the two domains conforming the metaphor are rendered by way of metonymy. In the first figure, a piano pointing to the domain of music and a watch pointing to the domain of time. In figure 2, the use of the cream, which stands for losing weight, and the bicycle, which stands for the path to be followed. Thus, the mechanism of metonymy is a potentially rich linguistic resource in the understanding of the advertising discourse as seen in both advertisements.

As advocated by Black (1993), similarity between the two terms of the metaphor is typically created rather than preexistent. If we go over the different advertisements, we can see that in none of them the similarity is already available at first sight; rather it has been forced into the picture. The reason why that similarity can be imposed between the two terms is because the advertiser relies on the verbal component, which clearly establishes the link created between the two domains. Thus, in both, figure 1 and figure 2 , the verbal message is a key ingredient to fully grasp the message.

At any rate, it is true that in figure 2, the viewer, relying on world knowledge, could establish some kind of connection between the entities in the picture without accessing the information provided in the written message. That is to say, if we take for granted the cream portrayed is to fight cellulite, which seems a very intuitive thought being closed to a very slim figure, we know that one of the benefits proclaimed by anticellulite creams is that they reduce one's body fat. Concerning figure 1, this advert conducts a more sophisticated projection from one domain to the other; in other words, this mapping becomes possible only through relying on the verbal component as, otherwise, no connection would be established in the minds of consumers.

Regarding the two hypotheses advanced at the beginning of this paper, it can be said that, in relation to the first one, that the use of multimodal metaphors are an effective way to attract and maintain viewer's attention due to the novelty of the message and creative link established between the two domains of the metaphor; and it is equally true that they contribute to transmit a very positive image of each of the products advertised by associating them to very desirable qualities hoping to persuade the viewer into buying them. The magical link triggered in the minds of consumers is that, for instance, by purchasing those products they will either incarnate the elegance and distinction exhibited by the pianist Lang Lang in figure 1, or the perfect shape of the woman in figure 2. Those values, transmitted through the advertisement of the products, reflect the expected and praised patterns of behaviour of the members of the community where the products are on sale (Kövecses, 2005). As regards the second hypothesis, the authorial voice, that of the advertiser, and its value position concerning the product advertised is always, on purpose, delegated to somebody else; either to the voice of an expert: a world renowned pianist (figure 1) for a very expensive product, since a lot of reassurance is needed to purchase that product, or the team of researchers 
of the pharmaceutical company (figure 2) for a product in a medium-range price. In both cases the strategy confers objectivity to the products.

Since the nature of this type of discourse is persuasive, all the emphasis is placed on the very attractive and desirable qualities of one particular product; thus, the "orientation toward unity" (Bakhtin, 1981: 274) - or the orientation toward the advertised product as the only one deserving praise- leads to a monoglossic or undialogised situation, where no competing products are represented, which is, of course, to the advertiser's benefit. Thus, the voice of the advertiser, hidden behind the identity of another self, presents the product advertised as the exclusive and only answer to a given situation or problem.

Multimodal metaphors which join verbal and pictorial elements, as in the two adverts seen, seem a very effective strategy used in the advertising discourse to trigger a richer and stronger emotional appeal by building on two sign systems which work in a complementary manner, strengthening the final message. Besides, it must be said that the pictorial component helps in giving the message a perceptual immediacy, with a high degree of specificity, which cannot be attained by just focusing on the verbal element (Forceville, 2008).

\section{Conclusions}

Building on the claim made by Forceville repeatedly in his different works that the study of metaphor should not be restricted to language but, rather, that it is necessary to refine and test the theory of conceptual metaphor, initially introduced by Lakoff and Johnson (1980), to find evidence of the existence of conceptual metaphor in other areas such as pictures, images, sounds or music, for example, this paper, hopefully, contributes to show once again that metaphor, as a cognitive phenomenon (Lakoff and Johnson, 1980, 1999, 2003), is also pervasive in the field of advertising, where images and language are put together. With this idea in mind and trying to further the study, I have put to use an analytical tool which brings together two linguistic approaches, cognitive linguistics and systemic functional linguistics, in an attempt to have a more insightful approach when interpreting texts which, as advertising, combine visual and verbal modalities.

As for the nature of the advertising discourse, it has become clear that the aim is to make an impact on viewers so that the advertisement will not go unnoticed. As a result, the cognitive effects (Sperber and Wilson, 1986) resulting from the viewer being involved in the processing of all the visual and verbal information packed in the advert are expected to play a role in making viewers remember the advertisement longer. As part of the cognitive effects intended, the metaphors activated in understanding each advertisement serve to persuade and influence readers' behaviour and lead them to the position which the advertiser has intended. Consequently, metaphors are persuasive resources (Goatly, 2007) because of the emotional force that they carry, transforming the ordinary into something extraordinary. This idea is in tune with the ultimate goal of 
the advertiser, which is, relying on all the cognitive significance of metaphors, move their audiences into buying the product.

Adding the resource of evaluation to that of metaphor in an integrated fashion seems to have given insightful results when it comes to understanding what the intended effects on the viewer were. Thus, issues such as those of the stance of the advertiser in relation to the message being launched and the relationship intended with the putative reader contribute a great deal to the understanding of the cognitive effects brought about on the viewer after being exposed to the adverts.

As for the limitations of this study, it can be said that a bigger number of advertisements is needed in order to find out if a number of systematic patterns arise in this type of discourse. Consequently, once a corpus has been gathered, future research is expected to move in the line of considering if, for example, certain source domains are typically used to promote some product categories such as beauty products, or if, for instance, any differences appear between the source domains being chosen to advertise products for either females or males.

\section{Notes}

1. Dialogism is the characteristic epistemological mode of a world dominated by heteroglossia. Everything means, is understood, as a part of a greater whole -there is a constant interaction between meanings, all of which have the potential of conditioning others. Which will affect the other, how it will do so and in what degree is what is actually settled at the moment of utterance. (Bakhtin, 1981: 426).

\section{References}

Bakhtin, Mikhail (1981): The Dialogic Imagination (translated by C. Emerson and M. Holquist). Austin: University of Texas Press.

Barthes, Roland (1978): Image, Music, Text (translated by Stephen Heath). New York: Hill and Wang.

Black, Max (1993): "More about metaphor." In A. Ortony, ed., Metaphor and Thought. New York: Cambridge University Press, 20-41.

Carroll, Noel (1994). Visual metaphor. In. J. Hintikka ed., Aspects of metaphor. Dordrecht: Kluwer, 189-218.

Cortés de los Ríos, María Enriqueta (2010): "Cognitive devices to communicate the economic crisis: An analysis through cover in The Economist." Ibérica 20: 81-106.

Forceville, Charles (1994): "Pictorial metaphor in advertisements." Metaphor and symbolic activity 9(1): 1-29.

Forceville, Charles (1996): Pictorial metaphor in advertising. New York: Routledge.

- (2006): "Non-verbal and multimodal metaphor in a cognitivist framework: Agendas for research." In G. Kristiansen, M. Archand, R. Dirven and F. J. Ruiz de Mendoza Ibáñez, eds., Cognitive Linguistics: Current Applications and Future Perspectives. Berlin: Mouton de Gruyter, 379-402. 
(2007): Multimodal metaphor in ten Dutch TV commercials. Public Journal of Semiotics, 1, 19-51.

(2008): "Metaphor in Pictures and Multimodal Representations." In R. Gibbs Jr. ed., The Cambridge Handbook of Metaphor and Thought. Cambridge: Cambridge University Press, 462-482.

Gibbs, Raymond (1994): The Poetics of Mind. Cambridge: Cambridge University Press.

Goatly, Andrew (2007): Washing the brain: Metaphor and hidden ideology. Amsterdan/Philadelphia, PA: John Benjamins.

Herrera, Honesto and Michael White (2012). Metaphor and Mills: Figurative Language in Business and Economics. Berlin/Boston: Walter de Gruyter.

Hawkins, Bruce (2001): "Ideology, metaphor and iconographic reference." In R. Dirven, R. Frank and C. Illie, eds., Language and Ideology II. John Benjamins Publishing Company: 27-50.

Hunston, Susan (2003b): "Evaluation and the planes of discourse: status and value in persuasive texts." In S. Hunston, and G. Thompson, eds., Evaluation in text. Authorial stance and the construction of discourse. Oxford: Oxford University Press.

Hunston, Susan and Geoffrey Thompson, eds. (2003a): Evaluation in text. Authorial stance and the construction of discourse. Oxford: Oxford University Press.

Johnson, Mark (1987): The Body in the Mind. The Bodily Basis of Meaning, Imagination and Reason. Chicago: The University of Chicago Press.

Kennedy, John (1982): “Metaphor in pictures.” Perception 11: 589-605.

Kovecses, Zoltan (2002): Metaphor. A Practical Introduction. Oxford: Oxford University Press. (2005): Metaphor in Culture. Cambridge: Cambridge University Press.

Lakoff, George (1987): Women, Fire and Dangerous Things. Chicago: The University of Chicago Press.

- (1993): "The contemporary theory of metaphor." In A. Ortony, ed., Metaphor and Thought. Cambridge: Cambridge University Press, 202-251.

(2004): Don't think of an elephant: Know your values and frame the debate. Chelsea Green Publishing: New York.

Lakoff, George and Mark Johnson (2003): Metaphors We Live by. Chicago: The University of Chicago Press. (Original work published 1980).

(1999): Philosophy in the Flesh. The Embodied Mind and its Challenge to Western Thought. New York: Basic Books.

Lakoff, George and Mark Turner (1989): More than cool reason: a field guide to poetic metaphor. Cambridge: Cambridge University Press.

Lakoff, George and Núñez, Rafael (2000): Where Mathematics Comes From: How the Embodied Mind Brings Mathematics into Being. New York: Basic Books.

Martín de la Rosa, Victoria and Luis Miguel Lázaro Lorente (2011). "The Race to Educational Reform in the USA: the race to the top." Language and Education 479-490

Martin, J. Robert and Peter White (2005): The language of evaluation. Palgrave Macmillan.

Ortony, Andrew (1993): Metaphor and Thought. Cambridge: Cambridge University Press.

Richards, Ivor Armstrong (1971): The philosophy of rhetoric. New York: Oxford University Press. (Original work published 1936).

Ruiz de Mendoza Ibáñez, Francisco José (1999a): Introducción a la Teoría Cognitiva de la Metonimia. Granada: Método.

(1999b): "From semantic underdetermination via metaphor and metonymy to conceptual interaction." Laud 492: 1-21. 
Sperber, Dan and Deirdre Wilson (1987): "Précis of Relevance: Communication and Cognition." Behavioural and Brain Sciences 10(4): 697-710.

Taylor, John (1995): Linguistic Cross-categorization. Prototypes in Linguistic Theory. Oxford: Clarendon Paperbacks.

White, Michael (1997): "The use of Metaphor in Reporting Financial Market Transactions." Cuadernos de Filología Inglesa 6(2): 233-245.

\section{APPENDIX}

Sources of advertisement illustrations:

\section{Figure 1}

Advertiser: MONTBLANC; Product: MONTBLANC Star Nicolas Rieussec Monopusher Chronograph ;

- Gentleman. Número 62 [Issue 62] (p. 47).

\section{Figure 2}

Advertiser: Clarins; Product: Lift-Minceur Haute Définition;

- Telva. Número 840 abril 2009 [Issue 840 April 2009] (p. 219). 